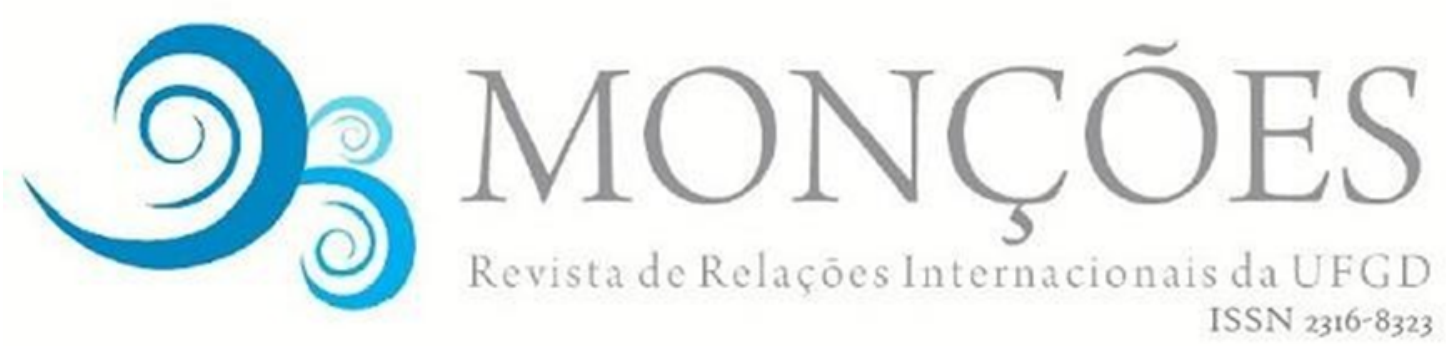

\title{
CRIMEN ORGANIZADO: CONFRONTANDO LA PERSPECTIVA SECURITIZADORA CON LOS APORTES SOBRE STATE-CRIME COLLUSION. IMPLICACIONES DISCIPLINARES ${ }^{1}$
}

MARINA VITELLI

Universidade Federal de São Paulo (EPPEN-UNIFESP), Programa de Pós-Graduação 'San Tiago Dantas' (São Paulo, SP, Brasil) e Grupo de Estudos de Defesa e Segurança Internacional (GEDES), São Paulo (SP), Brasil. ORCID: http://orcid.org/0000-0001-8827-6279. marina.vitell@unifesp.br

SUZELEY KALIL MATHIAS Universidade Estadual Paulista (UNESP), Programa de Pós-Graduação 'San Tiago Dantas', Departamento de Relações Internacionais da Faculdade de Ciências Humanas e Sociais (DERI-FCHS) e Grupo de Estudos de Defesa e Segurança Internacional (GEDES), São

Paulo (SP), Brasil. ORCID: http://orcid.org/0000-0003-0354-9675. suzeley.kalil@unesp.br

HELENA SALIM DE CASTRO

Programa de Pós-Graduação em Relações Internacionais 'San Tiago Dantas' (UNESP, UNICAMP, PUC-SP), Grupo de Estudos de Defesa e Segurança Internacional (GEDES UNESP) e Núcleo de Estudos Transnacionais da Segurança (NETS - PUC/SP), São Paulo (SP), Brasil.

ORCID: https://orcid.org/0000-0003-3059-2150 helena.castro@unesp.br

Resumen: Este trabajo ofrece un análisis crítico respecto de lo que identificamos como la perspectiva securitizadora del crimen organizado, la cual se ha fortalecido dentro del área de estudios sobre seguridad y defensa de América Latina. A pesar de su énfasis en un elemento propio de la ampliación de la seguridad - las amenazas no estatales transnacionales en lugar de conflictos militares interestatales - argumentamos que la misma continúa anclada en la visión tradicional, estatista y militarista propia de la noción de seguridad nacional. Llamamos la atención, a su vez, sobre la conexión entre dicha perspectiva y la agenda de las Relaciones Internacionales como disciplina. En contraste, defendemos la necesidad de agregar contribuciones de la Ciencia Política y la Sociología - entre otras áreas - que permiten una visión más precisa de la relación existente entre crimen y estado en América Latina. Puntualmente, confrontamos la perspectiva securitizadora con la literatura sobre state-crime collusion para mostrar el papel instrumental que las organizaciones criminales juegan en la gobernabilidad de los territorios en países con déficits democráticos y de nivel de desarrollo.

\footnotetext{
${ }^{1}$ Agradecemos a los revisores anónimos, cuyos comentarios ciertamente tornaron mucho más claro este artículo, inclusive para sus autoras.
} 
Para ilustrar nuestro argumento recurrimos a investigaciones sobre dos importantes organizaciones criminales de Brasil: el Comando Vermelho y el Primer Comando de la Capital.

Palabras clave: Narcotráfico; Colusión; Brasil.

\title{
ORGANIZED CRIME: CONFRONTING THE SECURITIZING PERSPECTIVE WITH STATE-CRIME COLLUSION LITERATURE. DISCIPLINARY IMPLICATIONS
}

\begin{abstract}
This article offers a critical analysis of what we identify as the securitizing perspective of organized crime, which has become widespread within the area of Latin American security and defense studies. Despite its emphasis on a feature of the widening of security - non-state transnational threats rather than interstate military conflicts - we argue that it continues to be anchored in the traditional, statist and militaristic view of the notion of national security. We call attention, in turn, on the connection between this perspective and the International Relations agenda as a discipline. In contrast, we advocate the need to add contributions from Political Science and Sociology - among other disciplines - that allow a more accurate view of the relationship between crime and state in Latin America. Specifically, we confront the securitizing perspective with the literature on state-crime collusion to show the instrumental role that criminal organizations play in the governance of territories in countries with democratic and developmental deficits. To illustrate our argument, we turn to investigations on two important criminal organizations in Brazil: the Comando Vermelho and the Primeiro Comando da Capital.
\end{abstract}

Keywords: Drug-trafficking; Collusion; Brazil.

\section{CRIME ORGANIZADO: CONFRONTANDO A PERSPECTIVA SECURITIZADORA COM AS CONTRIBUIÇÕES SOBRE STATE-CRIME COLLUSION. IMPLICAÇÕES DISCIPLINARES}

Resumo: Neste artigo oferecemos uma análise crítica sobre o que identificamos como a perspectiva securitizadora do crime organizado, que vem se fortalecendo na área de estudos de segurança e defesa na América Latina. Apesar de sua ênfase em um elemento próprio da ampliação da segurança - as ameaças transnacionais não-estatais em vez de conflitos militares interestaduais - argumentamos que ela continua ancorada na visão tradicional, estatista e militarista, própria da noção de segurança nacional. Ao mesmo tempo, chamamos a atenção para a conexão dessa perspectiva com a agenda das Relações Internacionais como disciplina. Em contrapartida, defendemos a necessidade de agregar contribuições da Ciência Política e da Sociologia, entre outras áreas, que permitam uma visão mais precisa da relação entre o crime e o Estado na América Latina. Especificamente, confrontamos a perspectiva securitizadora com a literatura sobre conluio Estado-crime (state-crime collusion) para mostrar o papel instrumental que as organizações criminosas desempenham na governança de territórios em países com déficits democráticos e de desenvolvimento. Para ilustrar nosso argumento, recorremos às investigações sobre duas grandes organizações criminosas brasileiras: o Comando Vermelho e o Primeiro Comando da Capital.

Palavras-chave: Narcotráfico; Conluio; Brasil.

\section{INTRODUCCIÓN}


Durante las últimas décadas, la temática del crimen organizado - en particular el tráfico internacional de drogas - ha ido ganando espacio como objeto de análisis de los estudios latinoamericanos de Seguridad Internacional, sub-área de la disciplina de las Relaciones Internacionales (BUZAN; HANSEN, 2012). Entre esos estudios, a efectos de este trabajo, destacamos una perspectiva - presente tanto en el medio académico como en los debates públicos - que caracteriza al crimen organizado como una amenaza transnacional a la seguridad de los países de América Latina, mucho más palpable que los conflictos interestatales. Diferentemente de las tradicionales disputas por recursos, poder e influencia entre los países, el crimen se configura como un peligro más urgente, constituyendo un enemigo novedoso: un actor no estatal, con vínculos transnacionales, que en ocasiones posee mayor poder de fuego que el propio Estado.

En términos generales, esta perspectiva entiende que, en la medida en que el crimen organizado pone en jaque el monopolio estatal de la violencia legítima, la soberanía nacional y la integridad territorial, el problema se transforma en una amenaza a la seguridad nacional, tornando necesaria la adopción de una estrategia militar para su eliminación, incluyendo el empleo de las fuerzas armadas, tanto en tareas subsidiarias como en roles de protagonismo. Como consecuencia, a partir de este diagnóstico, el problema del crimen organizado suele ser concebido en términos de seguridad y defensa.

Este razonamiento refleja en gran parte la visión tradicional sobre la seguridad internacional que predominó en los estudios del área hasta la década de los 80 . Dicha perspectiva privilegiaba la seguridad del Estado-nación, preponderantemente amenazada por otros Estados como resultado de las dinámicas propias del sistema internacional anárquico, básicamente, la lucha por el poder y la supervivencia entre los estados. Esta perspectiva enfrentó varias resistencias provenientes de diversas visiones que en las postrimerías de la Guerra Fría protagonizaron el movimiento conocido como "ampliación y profundización" del concepto de la seguridad (BUZAN et al, 1998;). En pocas palabras, y a riesgo de simplificar una perspectiva sumamente compleja, el Estado-nación fue cuestionado en tanto principal objeto referente de la seguridad: este podría, inclusive, ser la principal fuente de inseguridad para otros 
sujetos posibles, tales como los individuos o la humanidad en su conjunto. A su vez, sea cual fuere el objeto de referencia de la seguridad, las amenazas enfrentadas por Estados, individuos, grupos o la raza humana ya no provenían principalmente de las dinámicas del conflicto interestatal, sino de problemáticas y actores no estatales con actuación transnacional: organizaciones criminales, terroristas y empresas con prácticas económicas insostenibles para el medio ambiente, entre otros.

A partir de esta complejización de la agenda, parte de la disciplina de las Relaciones Internacionales comenzó a prestar atención a fenómenos con claras dinámicas transnacionales - esto es, que ponen en interacción intensa y regular a actores no estatales en distintos países - que resultaban amenazantes para los Estados, sus ciudadanos y a la humanidad en su conjunto. En lo que respecta al crimen organizado, el tráfico global de drogas aparece como un fenómeno que involucra organizaciones con claras vinculaciones a través de las fronteras, tanto por la construcción de cadenas de producción, distribución y venta del producto, así como del lavado de activos que produce, íntimamente vinculado al sistema financiero internacional. Aun reconociendo la relevancia del elemento transnacional, en este artículo llamamos la atención sobre una consecuencia negativa del estudio del crimen organizado por parte del área de la Seguridad Internacional. Partimos, así, de la premisa de que, a pesar de estudiar una amenaza no-estatal, dentro de dicha área se ha fortalecido una perspectiva sobre el crimen organizado que es propia de la visión tradicional de la seguridad - estado-céntrica y militarista - la cual resulta fundamental para legitimar las estrategias militarizadas del combate al crimen que forman parte del régimen internacional de lucha contra el narcotráfico, construido desde las Naciones Unidas. En contraposición, defendemos que los supuestos centrales de los estudios críticos de seguridad permiten una visión alternativa, aunque alejan la temática del área de Relaciones Internacionales, acercándola a otras disciplinas como la Ciencia Política, la Sociología y la Antropología.

En otras palabras, y a modo de provocación, en este trabajo colocamos la siguiente pregunta: ¿precisamos retirar el tema del crimen organizado de la agenda de las Relaciones Internacionales? En respuesta a este interrogante, argumentamos que resulta necesaria una reformulación de los supuestos de la perspectiva favorable 
a la militarización - que denominamos perspectiva securitizadora - a partir de una mejor comprensión sobre la relación entre organizaciones criminales y gobierno de territorios a partir de la colusión entre criminalidad y estado. Mientras que la primera supone la separación entre lo criminal y lo estatal, la segunda enfatiza que crimen y estado confluyen para crear órdenes mutuamente beneficiosos (aunque perjudiciales para los ciudadanos), poniendo de relieve tanto el papel instrumental que las organizaciones criminales juegan en la gobernabilidad de los territorios en países con déficits democráticos y de nivel de desarrollo, como la dependencia que el crimen tiene en relación a las estructuras de estado. Esta realidad es más fácil de comprender recurriendo a desarrollos de la Ciencia Política, la Antropología y la Sociología, más que de las Relaciones Internacionales. Aún así intentaremos a lo largo del texto enfatizar las contribuciones de la disciplina.

Para ilustrar nuestro argumento, recurrimos como referente empírico al caso brasileño. Este país sufre de tasas de homicidio dignas de territorios en guerra. Sus principales organizaciones criminales no paran de crecer, habiendo llegado a establecer un férreo control sobre diversos espacios, incluyendo las prisiones. Como respuesta a esta emergencia, distintos gobiernos optaron por emplear a las fuerzas armadas brasileñas en tareas de seguridad pública, tanto en áreas urbanas como de frontera, adoptando el discurso de la amenaza a la seguridad nacional. A pesar de sus especificidades, en este trabajo utilizamos al caso brasileño para entender las limitaciones generales de la visión sobre el crimen organizado de corte militar asociada al concepto de seguridad nacional y presentar una perspectiva alternativa que subraya las variables políticas domésticas: la relación simbiótica entre crimen y gobernabilidad ofrecida por la literatura de state-crime collusion.

Con este propósito, el artículo comienza presentando un análisis crítico sobre la perspectiva securitizadora del crimen organizado, contrastándola con la perspectiva denominada state-crime collusion. A continuación, estos argumentos conceptuales son aplicados al caso brasileño, comenzando por el análisis de las características generales del crimen organizado en este país, realizando referencias al modus operandi de dos de las organizaciones criminales más importantes: el Primeiro Comando da Capital (PCC) y el Comando Vermelho (CV). La elección de estas 
organizaciones no fue aleatoria. Ambas son organizaciones criminales con importantes incursiones internacionales, un actor no estatal violento, con nula o limitada reivindicación política, cuyo principal objetivo son las ganancias económicas para sus integrantes (FERREIRA, FRAMENTO, 2019, p. 93). El análisis del accionar de ambos grupos y las respuestas del estado brasileño apunta a la existencia de una serie de prácticas de beneficio mutuo, propias de la dinámica de state-crime collusion, un fenómeno que para ser detectado necesita del aporte de conceptos y debates politológicos, sociológicos y antropológicos.

\section{La perspectiva securitizadora ${ }^{2}$ del crimen organizado y el corolario de la militarización como estrategia}

A pesar de ser producto de una construcción en varias etapas, es posible identificar el origen de la perspectiva securitizadora del crimen organizado en los procesos dinamizados a partir de la post Guerra Fría. El fin del conflicto entre comunismo y capitalismo, la instauración de gobiernos democráticos y la resolución pacífica de conflictos entre estados pusieron en cuestión los dos fenómenos que hasta el momento eran tenidos como amenazas por parte de los países de la región: las organizaciones armadas insurgentes y las disputas fronterizas interestatales y otras rivalidades políticas. En este marco, y en el contexto de los organismos específicos de la Organización de Estados Americanos (OEA), los países de la región, bajo fuerte influencia de los Estados Unidos ${ }^{3}$, formularon el concepto de la seguridad

\footnotetext{
${ }^{2}$ No cabe aquí un análisis completo de los diversos procesos de securitización de las drogas. Para los fines aquí buscados, entendemos a la securitización como "[...] un movimiento discursivo que pretende presentar una amenaza con respecto a una situación u objeto, con el objetivo de elevarla más allá del campo de la política, utilizando, por lo tanto, el uso de medidas excepcionales [...] "(MOTTA, 2018, [p. 1006]). Siguiendo la traducción de la Escuela de Copenhague, la securitización es un proceso que involucra desde el objeto de referencia, el agente de securitización que, a través del habla (acto del habla) llega a una audiencia que percibe el objeto nombrado por el agente como amenaza (MOTTA, 2018, [pág. 1006])

${ }^{3}$ La influencia del liderazgo estadounidense en la elaboración y mantenimiento de agendas de seguridad en las Américas puede ser observada en el caso de la definición del concepto de Crimen Organizado Transnacional y, más específicamente, del consumo y tráfico de drogas como una amenaza regional e internacional - lo que impulsó la imitación de la política de "guerra contra las drogas" en todo el continente (RODRIGUES, 2012). En el caso específico del crimen organizado, Pereira (2015) analiza cómo una serie de políticas e intereses domésticos en los Estados Unidos, principalmente a partir de los años 1990, impulsaron las discusiones sobre el concepto y actuación del
} 
multidimensional, la cual incluiría tanto las amenazas tradicionales como las nuevas, entre ellas, el crimen organizado, el tráfico de drogas y el terrorismo (SAINT-PIERRE, 2011; VITELLI, 2016; DONADELLI, 2018).

Conforme fue desarrollándose el concepto de seguridad multidimensional a nivel de las organizaciones regionales, surgieron trabajos que tradujeron las discusiones realizadas por los países hemisféricos en análisis académicos dentro del área de las Relaciones Internacionales y la seguridad internacional. Aun tratándose de reflexiones heterogéneas, en este artículo argumentamos que es posible identificar en ellas como elemento común un razonamiento que interpreta un grave problema político y social como una amenaza a la seguridad nacional, movimiento analítico necesario para la aceptación de una estrategia militar como solución pragmática del problema.

Esta perspectiva securitizadora del crimen organizado parte de la premisa de que en la región existen territorios desgobernados (PREVOST et al, 2014; PIMENTA, 2016) en donde operan organizaciones criminales que - en función del control territorial que ejercen y del empleo de violencia armada - disputan con el estado el monopolio de la fuerza (SAMPÓ; TRONCOSO, 2015), amenazando la soberanía y erosionando la capacidad estatal de ejercer autoridad, adoptando así atributos de las organizaciones insurgentes (REALUYO 2015; 2018). En el marco de esta contextualización, por ejemplo, existen trabajos que analizan el caso mexicano y argumentan que, en dicho país, el crimen organizado afecta la gobernabilidad al erosionar la capacidad estatal de ejercer la autoridad sobre el territorio, en la medida en que las organizaciones criminales compiten con el Estado en la detención del monopolio de la violencia legítima. Así, la actividad criminal, cuya motivación es el lucro, adquiere gravedad tal que pasa a tener consecuencias políticas (BARTOLOMÉ, 2013; SULLIVAN, 2012).

De este modo, este tipo de análisis pone en primer plano casos en los cuales el Estado no lograría controlar amplios espacios geográficos - denominados también como zonas grises - que sirven de base a las organizaciones criminales, espacios

Crimen Organizado Transnacional en las agencias y foros de las Naciones Unidas, lo que permitió el delineamiento de instrumentos y acciones específicos para el combate contra esa amenaza. 
geográficos que pueden estar ubicados en zonas urbanas, rurales o en áreas de frontera, en las que no imperan las leyes del Estado (TORRES, 2019, p. 331). En otras palabras, los países de la región tendrían territorios bajo dominio de complejas y poderosas organizaciones criminales y, consecuentemente, el Estado estaría imposibilitado de entrar en dichas zonas para ejercer la soberanía, dictar la ley y garantizar los derechos de sus ciudadanos (PIMENTA, 2016). Tal escenario, en el cual el Estado enfrenta un actor armado no estatal en su territorio, tendría importantes semejanzas con la existencia de enfrentamientos con movimientos insurgentes, lo cual lleva a los analistas a utilizar términos como "narcoinsurgencia", "insurgencia criminal" y "mafia insurgente" (SULLIVAN; ELKUS, 2008; SULLIVAN, 2012; BARTOLOMÉ, 2017), en virtud de las consecuencias políticas de la búsqueda de control sobre los territorios necesario para ejercer sus actividades ilícitas. Así, a pesar de priorizar una amenaza propia de la ampliación de la seguridad, esta perspectiva continúa alineada con la visión tradicional de la seguridad al conservar como objeto referente ${ }^{4}$ al estado y a la acción militar como estrategia preferida.

Estas premisas tienen relaciones directas sobre las disciplinas. A pesar de tratarse de amenazas no estatales, los estados estarían viendo amenazados sus elementos centrales: integridad territorial, soberanía e independencia política. Un nuevo actor estaría colocando en jaque los baluartes tradicionales de la seguridad nacional, legitimando el estudio del crimen organizado dentro del área de la seguridad y la defensa. Por otro lado, la interacción constante a través de las fronteras de estos actores no estatales violentos e ilegales inmediatamente remite a diversas agendas de las Relaciones Internacionales: la necesidad de la cooperación internacional para

\footnotetext{
${ }^{4} \mathrm{Al}$ considerar al Estado como un objeto de referencia, los enfoques de Relaciones Internacionales se centran en las percepciones de amenazas construidas por organismos y agentes institucionales, marginando la comprensión de los actores civiles sobre qué es una amenaza o cuáles son las causas y consecuencias de la violencia. Para romper con este estadocentrismo, otras áreas de conocimiento enfatizan el uso de metodologías que se enfocan en individuos y grupos de la sociedad civil. Moser y Mcllwaine (2004), por ejemplo, adoptaron una metodología de investigación participativa para comprender la violencia urbana en ciertos espacios en Colombia y Guatemala. El objetivo es dar agencia e identidad a las percepciones de violencia de la población local. Con esto, es posible tener una comprensión más amplia de la complejidad e interconexión de los diversos tipos de violencia, así como sus diversas causas y consecuencias, presentes en la sociedad (MOSER; MCLLWAINE, 2004).
} 
la acción coordinada buscando su derrota; el trabajo policial concertado de ambos lados de las fronteras; la construcción de regímenes internacionales para su combate repartiendo costos y esfuerzos, y el conocimiento acabado del impacto de los flujos de recursos dentro del sistema financiero internacional.

En contraste con esta interpretación, otra parte de la literatura - proveniente no sólo de las Relaciones Internacionales, sino también del trabajo con otras disciplinas - ha presentado análisis bien diferentes con relación a dos ideas presentes en la perspectiva securitizadora que nos parecen problemáticas. Por un lado, la asociación entre crimen y motivación insurgente; por otro, la noción de que existe un espacio desgobernado y que el Estado no obtiene beneficios del dominio criminal sobre los territorios, a partir de la imposición de órdenes locales ilegales. Ambas nociones - que serán analizadas a seguir - constituyen elementos claves de la decisión de emplear a las fuerzas armadas en el combate al crimen organizado y resultan centrales para interpretar, sobretodo, la crisis de seguridad pública brasileña.

Sobre la primera cuestión, entendemos que la asociación analítica entre crimen organizado e insurgencia opera como un elemento adicional que justificaría las estrategias militarizadas. El problema es que el intento de asociar crimen organizado e insurgencia aparece marcado por una serie de contradicciones. En primer lugar, esa perspectiva sostiene que, a pesar de no tener un proyecto político ni voluntad de tomar el poder, las organizaciones criminales pueden ser consideradas como movimientos insurgentes, al tiempo que se admite la ausencia de aquello que forma parte esencial de la insurgencia: el objetivo político de sustituir al poder estatal. A las debilidades analíticas de dicha asociación deben agregarse inconsistencias en la presentación de referentes empíricos. Esta interpretación sobre el crimen organizado latinoamericano coloca al Cártel de Medellín como ejemplo histórico reciente de una organización criminal con intentos de participación en la política. A pesar del gran poder que el narcotraficante Pablo Escobar había construido sobre la región donde operaba, no deja de ser un caso particular, tanto debido a la personalidad megalómana de aquel líder criminal, como en función del marco temporal, siendo que desde 1993, cuando Escobar fue asesinado, el tráfico de drogas en la región pasó por importantes transformaciones. Como argumento adicional, y también partiendo del caso Escobar, 
Ios análisis sostienen que las bandas criminales sustituyen al Estado cuando proveen bienes sociales en las comunidades donde operan (BARTOLOMÉ, 2006), actividades que responden más a estrategias de negocio - a la necesidad de ejercer control sobre el territorio - que a preferencias ideológicas o activismo político.

Finalmente, cuando se señala el riesgo de convergencia motivacional entre criminales e insurgentes que podría derivarse de la interacción creciente, en el intento de demostrar la ambigüedad en la delimitación de organizaciones criminales y movimientos guerrilleros, se presentan dos ejemplos: las FARC y Sendero Luminoso (BARTOLOMÉ, 2013; SULLIVAN, 2012), ambos grupos insurgentes que utilizaron el tráfico para financiarse, hasta que en un momento esa actividad criminal se volvió más importante que la práctica política revolucionaria. El inconveniente surge cuando se utilizan esos ejemplos para fundamentar el concepto de narcoinsurgencia que apunta el hecho inverso: criminales que se transformaron en insurgentes políticos, lo cual no tiene hasta el momento un referencial empírico claro en la región.

A pesar de presentar una perspectiva alternativa a la securitización, autores como Lessing (2015) y Barnes (2017), parten de un punto en común a los trabajos arriba citados. Coinciden con estos en que separar la violencia criminal de la violencia política de los movimientos insurgentes en función de la distinta motivación no permite un análisis completo del fenómeno, oscureciendo el hecho de que la primera puede ser, efectivamente, un tipo de violencia política. Así, reconocen que la literatura sobre "narcoinsurgencia" tiene como ventaja poner de relieve las consecuencias políticas de la violencia criminal, dando importancia al hecho de que, como resultado de las estrategias para conseguir fines materiales, las organizaciones criminales pasan a enfrentar al Estado, inclusive con efectos similares en términos de state-building al de los grupos insurgentes. No obstante esto, existen diferencias importantes entre ambos tipos de violencia - política y criminal - que deben ser tenidas en cuenta para decidir sobre las políticas de enfrentamiento contra las organizaciones criminales.

Lessing (2015) explica esta diferencia a partir de la caracterización de la violencia propia de las organizaciones insurgentes como "wars of conquest", con una lógica de interacción estratégica diferente de la violencia criminal, caracterizada como "wars of constraint". Además de la motivación política de la violencia, la primera 
supone la posibilidad de una victoria decisiva, sea del estado, al derrotar al grupo insurgente, sea de estos últimos, al subvertir el status quo y reemplazar al gobierno. Por el contrario, las guerras criminales no serían guerras de conquista y sí de coacción/restricción, en las cuales el actor que enfrenta al estado busca limitar su accionar, restringir su comportamiento y afectar el resultado de las políticas. En el caso de las organizaciones criminales, esto se traduce en cercenar la capacidad estatal de fiscalizar la legalidad de los mercados y de procesar penalmente a los responsables. En este caso, la victoria decisiva sería o imposible o indeseada: la derrota de una o varias organizaciones criminales - en particular las de narcotráfico da lugar al surgimiento de otra, ya que continúa existiendo demanda por substancias ilegales. Así, la victoria como objetivo estratégico sería simplemente inalcanzable. Por otro lado, los cárteles no desean la victoria definitiva sobre el Estado, puesto que no tienen condiciones de sustituirlo completamente. Así, la función de la violencia en las "guerras criminales" es coercitiva, disuasoria en lugar de la obtención de la conquista definitiva.

En otras palabras, a pesar de considerar que la violencia criminal tiene efectos políticos, esta visión alternativa explica dichos efectos por las consecuencias, teniendo cuidado de no asimilar el accionar de las organizaciones criminales con la insurgencia política. Aun reconociendo los múltiples problemas políticos generados por las organizaciones criminales, entendemos que es necesario evitar confundir el hecho de que el crimen organizado tiene efectos graves sobre la política con una situación diferente: la existencia de una voluntad de subvertir el orden político, esto es, los mismos efectos que un grupo insurgente.

Siguiendo este razonamiento, Cepik y Borba (2011) argumentan que las organizaciones criminales se asemejan más a un parásito que a un predador, puesto que para existir el crimen organizado necesita la protección del Estado y la interacción con el mundo lícito. De esta manera, la racionalidad criminal es contraria al interés en destruir o reemplazar al Estado, por lo cual el crimen organizado actúa más como una fuerza conservadora del status-quo que como un actor insurgente. El crimen necesita instituciones estatales débiles, poco republicanas, que estén al servicio de gobernantes pasibles de corrupción o coacción, un estado que sea lo suficientemente 
débil como para no imponer la ley, pero lo suficientemente fuerte para garantizar un orden social injusto. En efecto, tal como argumenta Pearce, el Estado en América Latina adopta estrategias de combate o de cooperación con actores violentos ilegales con el objetivo de garantizar los intereses de las elites, las cuales, a diferencia de la experiencia europea, nunca pasaron por el proceso de civilinización. En la actualidad, dichas estrategias suelen consistir en el enfrentamiento violento, por medios legales e ilegales, de grupos sociales previamente construidos como ciudadanos de segunda. De esta forma, más que un "Estado que falla", en América Latina permite formas de violencia para el mantenimiento de órdenes sociales injustos, una "nueva forma perversa del Estado" (2010, p. 296).

De forma similar, otros especialistas analizan las estrategias militarizadas de enfrentamiento al crimen a partir de un concepto crítico de gobernanza. Desde esta visión, la inserción actual de los países de América Latina en el orden capitalista global apunta para una reconfiguración particular del Estado, fundada en una "estabilidad híbrida" que constituye una "nueva forma de gobernanza" (DEWEY, 2012 apud SAíN, 2017, p. 136) o "nueva gobernabilidad de la inseguridad social5" (WACQUANT, 2009 apud RODRIGUES, BRANCOLI, KALIL, 2018, p. 89), en el marco de la cual las autoridades gubernamentales también obtienen beneficios políticos. En las palabras de Saín (2017, p. 137): [...] el Estado construye cierta gobernabilidad sobre determinados espacios o relaciones sociales de manera legal e ilegal y en acuerdo con (o mediante imposiciones a) actores legales e ilegales [...]. Esa gobernanza corresponde a una nova forma de orden político, la 'crimilegalidad', como la define Schultze-Kraft (SAíN, 2017, p. 137), íntimamente ligada al fenómeno de la colusión entre crimen y estado. También habría un tercer aspecto, llamado "gobernanza de la seguridad", que se refiere a la coordinación de los diferentes agentes de seguridad

\footnotetext{
${ }^{5}$ El concepto de De Wacquant se adopta para reflexionar sobre el proceso de exclusión de ciertos actores considerados indeseables o peligrosos para las dinámicas sociales. Esta exclusión no significa la invisibilidad total de estos actores, sino su uso para "controlar y moldear a las clases trabajadoras al sufrir el abuso diario de las fuerzas de seguridad y de los grupos armados (legales e ilegales), la mano dura del sistema de justicia penal, aislamiento en barrios / guetos / barrios marginales, y finalmente entrada en los archipiélagos penitenciarios". (RODRIGUES; BRANCOLI; KALIL, 2018, p. 89, traducción propia).
} 
que, aunque no tienen los mismos objetivos, acuerdan un espacio común para la construcción de la paz (BRAGA, 2007, p. 138).

\section{Del Estado amenazado al estado socio necesario: los aportes del state-crime collusion}

Conforme esbozado en los párrafos precedentes, en contraste con la asimilación entre crimen organizado y amenaza a la seguridad nacional existe otra literatura que critica la visión dualista entre crimen y gobierno, entendiendo que el orden ilegal creado por las organizaciones criminales también genera beneficios para los intereses políticos de garantizar gobernabilidad en determinados territorios. Se trata de la perspectiva de state-crime collusion (DEWEY; MÍGUEZ; SAÍN, 2017), empleada por diversos autores para describir la relación entre organizaciones criminales y entidades estatales en América Latina. En esta sección utilizamos investigaciones realizadas a partir de la visión no dual entre crimen y política, la cual, entendemos, permite describir más fielmente la realidad de la criminalidad organizada existente en países como Argentina y Brasil, muy diferente a la imagen de un aparato estatal amenazado por los criminales desde fuera. La principal diferencia con la perspectiva securitizadora es que el foco del análisis está puesto en las interacciones estratégicas entre criminalidad y estado, entendidas a partir de los intereses convergentes y divergentes de las organizaciones criminales y de las autoridades gubernamentales y sus aparatos coercitivos, o sea, factores pertenecientes a la dimensión política y sociológica doméstica.

Marcelo Saín $(2017 ; 2015)$ ha aplicado esta perspectiva para identificar el doble pacto que existe en Argentina entre policía y criminales, y políticos y policía. El autor argumenta que en este país la clase política no necesariamente se involucra activamente en el crimen organizado, sino que lo que ocurre es que los gobernantes acaban siendo funcionales al delito en la medida en que delegan a la policía el manejo de la seguridad pública colocando como objetivo, no la eliminación de la criminalidad, sino sólo la preservación de la "gobernabilidad", entendida como la ausencia de grandes escándalos públicos y de revueltas sociales. Las policías, para cumplir ese 
mandato, acuerdan con las organizaciones criminales, organizado una serie de prácticas de regulación del crimen necesarias para que se cumpla el objetivo de los gobernantes. Algo muy similar ocurre en Brasil, donde los políticos respaldan organizaciones criminales (SCHWARCZ, 2019), como apuntan diferentes investigaciones del país que analizamos en la próxima sección. Pero, diferentemente del caso argentino estudiado por Saín, el involucramiento cada vez más masivo de las fuerzas armadas brasileñas en tareas de seguridad pública, torna a los militares - junto con las policías - actores centrales en la composición de la gobernabilidad de este país.

De esta manera, en contra del argumento de que el crimen organizado amenaza el monopolio de la violencia física del Estado moderno, Saín sostiene que en Argentina, por delegación de las autoridades políticas, la policía ejerce el monopolio del uso ilegal de la fuerza en el espacio regulado donde el crimen opera, y el monopolio de la invisibilización burocrática de los crímenes tradicionales y de los crímenes protegidos: aquellos cometidos por los poderosos (SAÍN; ARSLANIÁN, 2017). El resultado es el des-gobierno político y la gobernabilidad policial de la seguridad pública. El autor añade que la clase política no intenta una solución de fondo porque ello requiere tomar medidas económicas y políticas que afectan intereses de sectores muy poderosos. De esta manera, mientras que la visión tradicional apunta a la "ausencia del Estado" forzada por el poder de las organizaciones criminales, Saín - entre otros - sostiene que el Estado está presente, aunque de manera perversa, y no necesariamente bajo la figura de corrupción tradicional. Así, el problema es la actuación ilegal de los agentes del Estado para regular el crimen organizado por fuera de la ley, posibilitando no sólo su funcionamiento, sino también garantizando su expansión.

Investigadores sobre la crisis de seguridad pública de Brasil han presentado un cuadro similar al argentino. Muniz y Proença (2007), Desmond Arias (2006) en sus análisis sobre la realidad del crimen en las favelas de Río de Janeiro, y Feltran (2018) estudiando los barrios periféricos de San Pablo, han señalado que las demandas sociales de servicios que el estado deliberadamente desatiende - entre ellos la seguridad - son "mercantilizadas" y provistas por organismos ilegales con mayor o 
menor grado de coerción, pero siempre con la indispensable aquiescencia del estado 6 . La policía - en tanto institución y no apenas como algunas "manzanas podridas" - no sólo "deja hacer" a los criminales a cambio de sobornos, sino que a través de una variedad de prácticas (milicias) van aceitando un orden paralelo que sirve tanto a los negocios de las diferentes organizaciones criminales, cuanto a las autoridades que aprovechan ese orden para necesidades políticas. En una línea similar, reflexionando sobre la responsabilidad del pragmatismo de los políticos en la actual crisis de seguridad pública brasileña, Lima (2017) ha señalado que el recurso a operaciones de Garantía de la Ley y el Orden en Brasil son estrategias de los gobernantes para evadirse de administrar las crisis, delegando esa función política a las fuerzas armadas ${ }^{7}$.

A pesar de no utilizar el concepto de state-crime collusion, Hristov (2014) trae un análisis similar al proponer analizar a los grupos paramilitares en Colombia rompiendo la mencionada dualidad entre Estado y crimen. Siguiendo a la autora, a lo largo de la historia colombiana los paramilitares han actuado en cooperación con los sectores políticos y de seguridad del país, con el objetivo no solo de enfrentar a la guerrilla, sino de garantizar las condiciones esenciales para la acumulación de capital. Estos grupos promueven el acaparamiento de tierras y luchan contra manifestaciones y revueltas contrarias a las políticas neoliberales implementadas por las élites locales y extranjeras (2014, p. 169) Además, para Hristov (2014), cuando estos grupos aplican instrumentos de coerción y coacción contra la población, eximen al Estado de esta "tarea", que permite que, incluso en un entorno con violaciones de los derechos

\footnotetext{
${ }^{6}$ En una línea similar, Perea conceptualiza la "dominación territorial violenta" para ilustra la inserción social de la "ilegalidad organizada" (2019: 261), factor central para entender la violencia extrema existente en varios países de la región. En resumen, para entender el nivel extremo de violencia debe comprenderse que los actores ilegales desempeñan funciones de control de los territorios tales como la imposición de normas, la resolución de problemas de la vida cotidiana de los habitantes y el arbitrio de conflictos; un fenómeno complejo, asociado a las características políticas, sociales y económicas de dichos países.

${ }^{7}$ El recurso a las operaciones de GLO comenzó a comprometer a las fuerzas armadas con el crimen, como muestra el episodio del transporte de drogas realizado por un sargento brasileño, utilizando la flota de la comitiva presidencial en viaje a España, en junio de 2019. Corrobora esta afirmación una investigación conducida por Arruda (2007), la cual demostró que, mientras en el pasado los crímenes más cometidos por militares eran la deserción y la insubordinación, en 2000 los mismos representaban $41 \%$ frente a $59 \%$ de acusaciones por robo, extorsión, estelionato, homicidio calificado y otros considerados graves.
} 
humanos, se pueda considerar que existe el mantenimiento de un régimen político formalmente democrático. Además de Colombia, este escenario se encontraría en toda América Latina, como en el caso de la relación entre grupos criminales y el Estado en Centroamérica y Brasil.

En resumen, estos investigadores han desafiado la idea de que el Estado en América Latina tiene la voluntad de hacerse presente en los territorios supuestamente copados por el crimen, una presencia que requeriría inversión de recursos económicos y riesgos políticos, y que se encontraría impedido de hacerlo en virtud del poder de fuego de las bandas criminales que los controlan, tal como plantea la lógica militar que ha venido siendo impuesta. En otras palabras, recurrir a una literatura alternativa a aquella asociada al concepto de multidimensionalidad de la seguridad y favorable a la participación de las fuerzas armadas en el combate contra el crimen organizado permite detectar inconsistencias en la representación más común del problema criminal de la región, aquí identificado como perspectiva securitizadora del crimen. En lugar de pensar con la lógica militar de territorios ocupados por fuerzas enemigas que disputan el poder con un estado cuyas fuerzas regulares no logran controlar, otras investigaciones apuntan a la existencia de órdenes particulares fruto de la connivencia entre el crimen y la política, una asociación que torna posible un cierto orden estatal, aunque difícilmente puede llamársele de orden democrático o republicano. Existe así una presencia territorial tanto del crimen como del estado interactuando bajo arreglos mutuamente beneficiosos, prácticas que van más allá de la corrupción entendida como soborno de autoridades públicas por parte de los criminales como será ejemplificado más adelante con referencias a la actuación de las dos organizaciones criminales más importantes de Brasil: el Comando Vermelho (CV) y el Primeiro Comando da Capital (PCC).

\section{Criminalidad y desigualdad en el orden socio-político brasileño ${ }^{8}$}

\footnotetext{
${ }^{8}$ Nota de agradecimiento a estudiantes y becarios por el levantamiento de datos.
} 
Trabajos recientes que adoptan la perspectiva de los estudios de paz para analizar la violencia criminal en América Latina han llamado la atención sobre cuán paradójico resulta caracterizar a la región como una zona de paz cuando algunos de los países que la forman tienen índices de violencia interna comparables con zonas de guerra (FERREIRA, 2019; KURTENBACH, 2019). En términos generales, esa literatura ha llamado la atención sobre la persistencia de un concepto minimalista de paz, que supone la coexistencia entre regímenes democráticos formales y niveles altos de violencia. A efectos de nuestro argumento, cabe mencionar la observación de Kurtenbach a respecto de la vinculación necesaria existente entre el mantenimiento y reproducción del status quo económico y social desigual - favorable a los intereses de determinadas elites - y la represión estatal (legal e ilegal), la violencia política selectiva y la corrupción (2019: 294). Así, entender la relación entre las múltiples violencias y las características propias del orden socio-político de algunos países de la región nos parece central para identificar las prácticas de state-crime collusion como estrategias de gobierno de las zonas grises, realidad que cuestiona la militarización del combate al crimen organizado propio de la perspectiva securitizadora.

En la combinación de paz externa y guerra interna, Brasil es un ejemplo paradigmático. Este país, el mayor de América del Sur, logró conformar su territorio habiendo vivido un único gran conflicto armado: la guerra contra Paraguay9. Considerando que se trata del tercer país con más vecinos fronterizos, es digno de destaque el hecho de que sus límites territoriales fueron establecidos por la diplomacia y no por la fuerza. En contraste, cuando se observa la paz interna, Brasil es un país de violencia endémica, siguiendo la definición que realiza la Organización Mundial de la Salud (OMS), aplicada a aquellas regiones con tasas mayores que 10 homicidios por 1000 habitantes. Según el informe divulgado en marzo de 2019 de la ONG

\footnotetext{
${ }^{9}$ A excepción de la guerra contra Paraguay que fue de hecho el conflicto más importante en América del Sur. La lucha por el control de la Plata marcó las relaciones entre Portugal y España durante la colonización de América del Sur. Sin embargo, las guerras que han conformado al territorio brasileño, promovidos antes de la independencia y, por lo tanto, por los portugueses, fueron, de hecho, genocidas, contra las poblaciones indígenas. La más conocida de esas masacres fue promovida conjuntamente por los gobiernos españoles y portugués contra las misiones guaraníes al sur del territorio brasileño, este de Argentina y Paraguay, en la región de la triple frontera, conocida como territorio de las misiones (LUGON, 1977).
} 
mexicana Seguridad, Justicia y Paz, 42 (84\%) entre las 50 ciudades más violentas del mundo están en América Latina y de estas 17 (40\%) están en Brasil. Cabe destacar que la investigación se realiza sólo en áreas urbanas, con base en las estadísticas producidas por órganos oficiales y, por lo tanto, revela apenas una pequeña parte de la identidad violenta de la sociedad brasileña. La violencia rural y contra pueblos originarios no son computadas por esta investigación, mientras que otros informes demuestran que viene creciendo ${ }^{10}$.

Esta violencia no es sólo endémica, sino también estructural, en los términos de Galtung (2003): aquella que se relaciona intrínsecamente con la ausencia de perspectivas de movilidad social, de acceso a servicios básicos y convivencia en ambientes violentos en forma de un ciclo de reproducción infinita, origen de culturas de violencia. En este contexto, los individuos están expuestos de forma cotidiana al racismo, la xenofobia, el sexismo, violaciones de derechos que crean y recrean esta estructura de violencia. En función de esto, Brasil bate récords de crímenes contra la mujer - ubicándose en el quinto lugar a nivel mundial - y contra personas LGBTi, según datos de la OMS (SCHWACZ, 2019).

En este marco de violencia y marginalidad, los espacios territoriales donde actúa el crimen organizado en Brasil precisan ser entendidos como resultado de la configuración social y política del país para comprender que no se tratan de zonas simplemente ocupadas por fuerzas criminales como si fueran ejércitos invasores, noción presente en la perspectiva de la seguridad multidimensional que justifica la militarización de la seguridad pública. Por el contrario, el estado histórica y deliberadamente se ausentó de aquellos espacios a los cuales quedaron confinadas las poblaciones excluidas.

\footnotetext{
${ }^{10}$ Es importante remarcar que, a pesar de que Brasil es un país urbano (el $85 \%$ del territorio es clasificado de esa forma por el Instituto Brasileiro de Geografia e Estatística), debe recordarse que los mayores conflictos son en tierras rurales, muchos de los cuales ni siquiera son reportados cuando suceden, sino que son dados a conocer mucho después. Sobre violencia rural, véase, por ejemplo, el informe realizado por Diaz para el Portal IG, disponible en $<$ https://www.cptnacional.org.br/component/jdownloads/ download/41-conflitos-no-campo-brasilpublicacao/14110-conflitos-no-campo-brasil-2017-web>. Y para pueblos originarios, https://cimi.org.br/wp-content/uploads/2018/09/Relatorio-violencia-contra-povos-indigenas 2017Cimi.pdf. Acceso en: 15/12/2018.
} 
Como bien muestra Jessé de Souza $(2015,2017)$, el trazo indeleble y fundante de la cultura de violencia en Brasil es la esclavitud, factor central para entender los espacios supuestamente desgobernados del país, hoy bajo control de las organizaciones criminales - como el Comando Vermelho e el Primeiro Comando da Capital. La estructura social establece una dinámica que paulatinamente amplía la exclusión social y marginaliza cada vez más a los individuos en esta situación. Las relaciones sociales y políticas son, todas ellas, mediadas por esta dinámica, creando niveles de ciudadanía, en cuyos escalones más bajos se encuentran los subciudadanos. Tales conciudadanos no son necesariamente los más pobres en términos de ingresos, sino los más excluidos de las políticas públicas.

Otro rasgo característico, que no es meramente una parte de la realidad política brasileña, sino que es constitutiva de la cultura y, en cierta medida derivada del primero, es la relación cercana de las fuerzas armadas con el poder político, producto de un proceso que se condensó en las cinco constituciones sancionadas apenas en cien años (MATHIAS; GUZZI, 2010). Este elemento fue un componente constitutivo del golpe de 1964 que erigió el autoritarismo burocrático y redundó en el control por parte de los militares de todo el proceso de transición hacia el gobierno democrático, incluyendo la imposición de la auto-amnistía y de funciones constitucionales para las fuerzas armadas que las mantienen como garantes de la legalidad y el orden. Asimismo, las fuerzas armadas representan una visión salvacionista de la autoridad política, independientemente de que esta autoridad sea parte del Estado o de un gobierno paralelo. La forma en que son educadas las fuerzas armadas nacionales para respetar la ley y someter cualquier ritual político también contribuye al diseño de las relaciones de poder. El comportamiento legalista de estas a menudo alimenta la extrapolación de la ley dentro de la legalidad - una paradoja nacional -, mientras que se garantiza la legitimidad de la acción en función de estar dictada por la ley ${ }^{11}$ (FERREIRA, 2000).

\footnotetext{
${ }^{11}$ Caso ejemplar de esto fue el devenir del régimen burocrático-autoritario (1964-1985) (O'DONNELL, 1986): el primer Acto Institucional no tenía número y tenía fecha para expirar; las élites buscaron rápidamente garantizar la normalidad, sometiendo a Castelo Branco al Congreso para ser alzado a la Presidencia de la República; mantuvieron la alternancia de poder, aunque restringida al sector
} 
Una particularidad que debe ser tenida en cuenta con relación a la organización del crimen en Brasil, y en particular en la ciudad de Río de Janeiro, es la existencia de las milicias ${ }^{12}$. Aunque no es posible trabajar el tema aquí, es importante al menos mencionarlas ya que estas componen una de las caras de la tragedia vivida por los sub-ciudadanos brasileños, formando parte de la trinidad que compone la política de inseguridad vigente en esas localidades. De hecho, tal como señala Schwarcz (2019, [p.126]) "las milicias no son solamente comandos regionales; funcionan con el respaldo de políticos y de líderes comunitarios", llegando a dominar el $41,6 \%$ de las favelas de Rio de Janeiro, mientras que el 55,9\% permanecía, a finales de 2009, bajo control de los narcotraficantes y por Unidades de Policía Pacificadora. Por su parte, Arruda (2007) apunta que las milicias ya penetraron las fuerzas armadas, en particular la baja oficialidad, como muestra el arresto del sargento que formaba parte de la comitiva que trasladaba al presidente Jair Bolsonaro a la reunión del G20 (RODRIGUES, 2019). En ese sentido, a juzgar por las denuncias, en particular, aquellas relacionadas con el asesinato de la legisladora municipal Marielle Franco, es posible conjeturar que el gobierno alimenta la presencia de estas milicias al interior del Estado brasileño.

La suma de estos elementos que constituyen relaciones sociales y políticas de forma jerarquizada y discrecional, combinada con otras que aquí no podemos abordar - como la expansión de las iglesias neo pentecostales -, conforman un pacto en el cual el balance del ejercicio del poder no está en la forma clásica de equilibrio entre los tres poderes de la República, sino en un sistema de frenos dobles: ningún gobierno cumple una agenda de grandes transformaciones sociales - para, así, mantener una

castrense, así como la existencia del sistema de partidos, aunque tutelado; buscaron legalizar la excepción por medio de otra Constitución (1967), etc.

${ }^{12}$ Las milicias están formadas por policías y bomberos militares, por carceleros, por individuos que pasaron por el servicio militar obligatorio, entre otros perfiles. Pueden estar ya jubilados u ofrecer sus servicios en horas de descanso. Venden, por medio de extorsión, servicios de protección a los habitantes de los barrios periféricos, pudiendo inclusive expandir los servicios a transporte clandestino que circula en el interior de las favelas cariocas, alquiler de inmuebles, conexión ilegal a los servicios de televisión por cable e internet, y cobro de peaje ilegal para el acceso a determinadas vías públicas. En otras palabras, las milicias están compuestas por individuos entrenados por el propio Estado cuya función debería ser la de mantener la ley, asegurando el ejercicio de los derechos del ciudadano. En contraste, abusan de los medios del Estado para actuar en contra de la ley, provocando mayor vulnerabilidad en aquellas poblaciones ya tan descuidadas (ZALUAR; CONCEIÇÃO, 2007). 
masa de sub-ciudadanos a disposición del clientelismo político y de la explotación capitalista -, pero por más reaccionario que sea un gobierno tampoco realiza un programa completamente neoliberal (GARZON, 2019).

En resumen, el sistema político en Brasil se erigió incluyendo lo que la literatura llama "zona gris" para representar la ausencia del Estado en regiones dominadas por el crimen. Nuestro argumento, sin embargo, es que dichos espacios no se explican en función de la incompetencia o falta de capacidad del Estado: su existencia y permanencia son parte constitutiva del sistema socio-político brasileño. De esta forma, no se puede considerar tales zonas como ingobernables o incluso sin gobierno. Por el contrario, su existencia resulta fundamental para el tipo de gobernabilidad desarrollada en Brasil, centrada en el ejercicio restringido de la política y en el acceso limitado a los bienes de la ciudadanía, factores que permiten el nacimiento de liderazgos salvadores, tanto regionales como nacionales, hoy sustituidos por el crimen organizado.

Dentro de este contexto socio-político, el crimen en Brasil está formado por más de ochenta organizaciones, cada una de ellas disputando entre sí, y algunas veces con el poder público, la hegemonía del crimen y la provisión ilegal de servicios públicos para la subciudadanía a lo largo y ancho del extenso territorio brasileño y, como algunos estudios han señalado, a través de las fronteras, constituyendo una empresa transnacional con sede en Brasil. En el intento de comprender cómo operan y cómo se relacionan con el poder público, se escogió para esta sucinta exposición las dos organizaciones más poderosas: el Comando Vermelho (CV) y el Primeiro Comando da Capital (PCC) $)^{13}$.

\section{Colaboración entre crimen y estado en Brasil}

\footnotetext{
${ }^{13}$ Hay una tercera fuerza criminal muy poderosa, la Familia do Norte (FN). Su estructura interna y su modus operandi es distinto de los dos otros. Sin embargo, es todavía una fuerza regional. Hoy disputa la triple frontera norte (Perú, Colombia y Venezuela) con PCC y CV. Hay un breve e importante análisis de esa organización criminal en SIQUEIRA; PAIVA, 2019.
} 
El CV fue la primera organización de envergadura orientada al mercado de drogas de Brasil. Nació en los años setenta bajo la influencia de los presos políticos alojados en la penitenciaría de llha Grande (AMORIM, 2018). Su actividad era básicamente el mercado minorista de drogas, especialmente marihuana, y la provisión ilegal de servicios esenciales para los habitantes de las favelas cariocas. En paralelo, estableció vínculos con los banqueros del juego del bicho, sociedad que generaba ganancias económicas mutuas, además de mantener los límites de la exclusión social, redundando en beneficios para la política de aquel momento. Asimismo, al atender demandas de las poblaciones de las comunidades periféricas, como acceso a servicios de energía, distribución de medicamentos - los cuales no eran ni son garantizados por el poder público - así como bienes ilícitos, parte del accionar del CV se revela como simbiótico con relación a los intereses de las autoridades. Su estructura, semejante a las mafias italianas, pero menos letal, permaneció fundamentalmente igual hasta los años 2000 (MANSO; DÍAS, 2018). A partir de ahí, la metodología se enfocó menos en el control territorial y más en la reglamentación de la actividad criminal (MANSO; DÍAS, 2018, p. 171).

En los mismos años en que el CV monopolizaba el mercado del crimen en Río de Janeiro, en San Pablo, diferentes grupos se disputaban el control del tráfico de drogas, funcionando como pequeños intermediarios del tránsito y del comercio al por menor, situación que agudizaba el clima de inseguridad que se expresaba en índices de criminalidad cada vez mayores. En esos años, entre 1980 y 1990, ocurrieron tres procesos simultáneos. En primer lugar, la adopción y profundización de una combinación de políticas estatales para el combate del tráfico de drogas: la represión ostensiva, la criminalización del comercio de pequeñas cantidades de drogas, el encarcelamiento masivo y la militarización policial. También data de esta época la transformación de Brasil de principal ruta de transporte para drogas en uno de los mayores mercados de consumo, ubicándose en el segundo puesto en materia de consumidores de cocaína en 2012 (LARANJEIRA et. al., 2014). Si a este panorama se le suma la "desigualdad abismal y visible a simple vista" (FELTRAN, 2018, p. 146), el resultado lógico es el escenario actual de la criminalidad brasileña. 
Esta realidad fue la propulsora de una nueva forma de organización del crimen, siendo la Masacre de Carandiru ${ }^{14}$ el detonador de la hegemonía del PCC. Concebida como un "sindicato del crimen", en un principio el PCC se propuso combatir los abusos de los agentes penitenciarios y organizar la convivencia entre los presidiarios. Con el tiempo, la organización fue adoptando tres pilares: a) es una sociedad estamental y, por lo tanto, basada en el honor, pero que a la vez cuenta con un estatuto que especifica al detalle las conductas permitidas y prohibidas entre los miembros de la facción; b) la descentralización del comercio ilegal de la seguridad y aplicación de la justicia para sus miembros y en los lugares en donde actúa; y c) la política de experimentación en sus acciones con el mercado legal y el Estado - tales como, ataques contra policías, secuestro de reporteros, corrupción de funcionarios y ocupación de cargos públicos, etc. Aquellas acciones que prueban ser exitosas se mantienen; las que fracasan, se abandonan. El primer y segundo pilar resultan fundamentales para entender las dinámicas de colusión con el estado, al mostrar que, tal como apuntó Willis, el PCC "modifica las relaciones sociales y ocupan un espacio central en la "gobernanza de las condiciones urbanas de vida y muerte" $(2015$, p. 9 , traducción propia).

Es posible entender hasta qué punto las dinámicas del PCC resultan funcionales a la gobernanza de los territorios cuando las comparamos con las prácticas del CV. La gran diferencia entre ambas está en la forma de pensar el territorio de actuación. La lógica del CV es empresarial y militar, lo que supone el control estricto de territorios por medio de las armas y de la imposición del miedo ("el morro tiene dueño"). Así, en las regiones controladas por el CV, la venta de cualquier producto o servicio, legal e ilegal, es controlada por sus jefes: ni siquiera se puede abrir una simple tienda de artesanía en los territorios controlados sin la anuencia del líder del CV local (AMORIM, 2018). En contraste, la lógica del PCC es aquella propia de las sociedades secretas, como la masonería (FELTRAN, 2018, 17). Su forma no

\footnotetext{
${ }^{14}$ La Masacre de Carandiru fue la matanza de 111 presos en la Penitenciaría de Carandiru, entonces la más grande prisión de América del Sur, en manos de la Policía Militar de São Paulo ocurrida en octubre de 1992.Cf. VARELLA, 1999. Esa fue la razón de la creación de una asociación destinada a la protección de los intereses de la masa carcelaria, que luego se convertiría en organización de tráfico, especialmente de drogas, pero también de otros bienes.
} 
es piramidal, sino celular (las células adoptan el nombre de "sintonías") y especializada en cada eslabón que compone la cadena criminal ${ }^{15}$. Son estas células que actúan en las prisiones y en los barrios bajo control del PCC, conectadas en forma de red y formando colectivos que establecen las decisiones a nivel regional, nacional e internacional. A pesar de organizarse en células, el PCC cuenta con un selecto grupo de presos responsables por decisiones estratégicas - como la incorporación de nuevos mercados para el crimen (rutas de la droga, por ejemplo) - llamada Sintonía General Final (SGF) y por el disciplinamiento de prisioneros de la propia cúpula, bajo el nombre de Resumen Disciplinar (MANSO; DIAS, 2018).

En particular, la forma en la cual el PCC lidia con la resolución de conflictos tanto entre sus miembros como en los territorios donde actúa es una de las principales prácticas que sirve también a los intereses de los gobiernos. Dicha organización cuenta con un código de conducta que vale sólo para los miembros, pero la facción también reivindica el monopolio de la aplicación de la justicia en los territorios cuando allí no está la policía. La paz se mantiene porque es la propia organización criminal la que garantiza los negocios. En otras palabras, el PCC reivindica el monopolio de la justicia en los territorios en que está presente y sólo en aquellos momentos en los que la policía está ausente (FELTRAN, 2018, p. 149). En función de esto, los investigadores han sostenido que la caída de $73 \%$ del índice de homicidios en San Pablo ocurrida desde 2001 se debe precisamente al papel regulador del crimen y de pacificación de las relaciones en los territorios desempeñada por el PCC, a partir de la implementación en las periferias de las reglas de control de la violencia que estableció dentro de las prisiones (WILLIS, 2015). De esta forma, la actuación de la organización criminal contribuye - si bien de forma ilegal - con el interés público de mantener una cierta gobernabilidad, reflejando la existencia de una relación de coalición entre crimen y estado.

En pocas palabras, los estudios han mostrado que el conjunto de prácticas impulsadas por el PCC dentro de las prisiones contribuye de forma sustancial a la relativa pacificación de las cárceles brasileñas, permitiendo al estado continuar la

\footnotetext{
${ }^{15}$ Existen entre otras la Sintonia de Bob, responsable del comercio minorista de marihuana, la Sintonia dos Gravatas, responsable de la contratación y pago de abogados, etc.
} 
política del encarcelamiento masivo en prisiones con pésimas condiciones de vida para los detenidos. Para mantener dicho status quo, las autoridades estatales llegan inclusive a favorecer a dicha organización criminal frente a otras. Recientemente, las decisiones sobre el líder del PCC Marcos Camacho (Marcola) parecen indicar, para algunos analistas, este tipo de práctica. Condenado a 300 años de prisión y preso desde 1999, Marcola pasó por diferentes prisiones de seis estados brasileños, habiendo pasado la mayor parte del tiempo en una cárcel de máxima seguridad en Presidente Venceslau, interior de San Pablo y luego enviado a la prisión federal de en Brasília. La transferencia de los líderes de las facciones busca desarticular la actuación criminal de la organización fuera de las cárceles, puesto que, a pesar de las restricciones de comunicación, se sabe que los miembros continúan actuando aun dentro de la prisión. Contrariamente al efecto buscado, la transferencia de líderes, como Marcola, contribuyó a la expansión de las facciones, incluido el PCC, a otros estados $^{16}$. Lo que es más, los especialistas apuntan que la política gubernamental de transferencia de presos problemáticos a otras cárceles posibilitó la alianza entre el CV y el PCC desde la creación de este hasta 2016, al permitir el contacto entre los 'hermanos' y de éstos con las demás facciones, haciendo escalar la organización del crimen para toda la federación (FELTRAN, 2018; MANSO; DÍAS, 2008; AMORIM, 2018).

A medida que las facciones crecían en número y en poder, aumentaba la competencia por el control del mercado, en especial el ingreso de drogas desde el exterior. Asimismo, la prohibición del uso de crack y el estricto control del mercado de drogas en las prisiones por parte del PCC, llevó a la ruptura de esta organización con el CV. Este rompimiento, sumado a la ausencia de políticas penitenciarias y de seguridad pública efectivas, ha redundado en la crisis carcelaria y en los episodios de escalada de la violencia especialmente en las regiones Norte y Nordeste del país, siendo las mayores masacres conocidas desde 2016 hasta hoy, que llevaron al

\footnotetext{
${ }^{16}$ La organización celular exige poca anuencia/permiso de la cúpula. Sin embargo, la circulación de sus miembros, especialmente de los líderes, estimula y fortalece novas adhesiones y los lazos con la organización.
} 
gobierno a incrementar el ya existente empleo de las fuerzas armadas para tratar de contener la matanza generalizada.

Las autoridades justificaron la transferencia de Marcola a partir del descubrimiento de un plan de fuga. Sin embargo, considerando que su primer destino fue Rondônia, es posible conjeturar que las autoridades deseaban promover la pacificación de las prisiones del norte del país, reveladas desde 2016. Conforme apuntan Ferreira e Framento (2019, p. 107), habiendo consolidado su hegemonía sobre la Ruta Caipira y siendo exitoso en la expansión de sus negocios, inclusive obteniendo el control de las prisiones de Paraguay y Bolivia (ABREU, 2018), el PCC pasó a disputar la Ruta del Solimões, anteriormente controlada por la Família do Norte $(\mathrm{FN})$, tercera mayor organización criminal del país y entonces aliada del $\mathrm{CV}$, pero actualmente compitiendo por el control de las prisiones con CV y PCC, con cierto éxito (SIQUEIRA; PAIVA, 2019). Este hecho desencadenó sangrientas rebeliones en diversas cárceles, hasta el momento no solucionadas por completo. La presencia de Marcola en una prisión del norte sugiere que puede haber una preferencia por el PCC, lo que podría llevar al debilitamiento, y quizás, desaparición de la FN/CV en esa región. Esta hipótesis refuerza la sugerencia de que existe una relación de colaboración entre crimen organizado y Estado.

En otras palabras, en sociedades fuertemente desiguales, como la brasileña, los organismos del estado no tienen la intención de "estar presentes" y "dominar el territorio" cuando eso significaría destinar recursos para garantizar a las poblaciones marginadas el acceso a derechos. En ese caso la presencia del estado se limita a lo justo y necesario para ganar las elecciones y prevenir tumulto social. En función de esta realidad, no existe tanto un problema militar de falta de control estatal sobre un territorio y sí una configuración social y política, sumamente perversa, pero sin posibilidad de ser resuelta con estrategias militares. Es un gravísimo problema político, de estado de derecho y políticas públicas (seguridad, salud, educación), pero no de seguridad nacional.

\section{Consideraciones finales}


A lo largo de este texto se buscó relativizar la visión tradicional sobre el crimen organizado en América Latina, caracterizada por una perspectiva militar sobre el fenómeno, la cual fundamenta, entre otras estrategias, el recurso a las fuerzas armadas para su combate. Por el contrario, propusimos una reinterpretación del fenómeno desde variables sociopolíticas: la relación de mutuo beneficio para los gobiernos y los criminales, desde que los primeros encuentran en los segundos socios para garantizar la gobernabilidad de los territorios sin necesitar invertir grandes recursos, resultando en la perpetuación de órdenes sociales excluyentes.

Aun reconociendo los múltiples problemas políticos generados por las organizaciones criminales, entendemos que es necesario evitar confundir el hecho de que el crimen organizado tiene efectos graves sobre la política con una situación diferente: la existencia de una voluntad de subvertir el orden político, esto es, los mismos efectos que un grupo insurgente. Así, mostramos que el intento de asociar crimen organizado e insurgencia aparece marcado por una serie de contradicciones analíticas y empíricas. Si bien considerar a la violencia criminal como política es relevante, en lugar de hacerlo a partir de encontrar elementos insurgentes en la misma, proponemos reflexionar sobre cuál tipo de orden socio-político dicha violencia torna posible y cómo esto lleva a descartar una estrategia militar de enfrentamiento con el crimen.

Utilizando las características y las dinámicas de las dos organizaciones criminales más grandes de Brasil, mostramos que, allí donde la visión de las "nuevas amenazas" identifica una situación militar de territorios dominados por el crimen, en los cuales las fuerzas estatales no logran ingresar para ejercer soberanía y monopolio de la violencia, en realidad existe un orden social injusto, violento y excluyente que la criminalidad organizada ayuda a gobernar, de manera perversa, aunque políticamente viable. En este contexto, gobernantes y criminales parecen más socios que enemigos, desmintiendo la idea de la insurgencia criminal y del Estado empeñado en hacerse presente como garante de derechos. Esta situación es socialmente crítica y moralmente injusta, afecta profundamente las bases de una paz positiva y debilita 
seriamente a la democracia, pero es muy diferente a la concepción estatista de las amenazas a la seguridad nacional que justifican el empleo de las fuerzas armadas para su conjuración. La transformación de los militares latinoamericanos en agentes de seguridad pública encuentra su justificación en un discurso securitizador del crimen que lo convierte en una amenaza existencial.

Para fundamentar este argumento, fueron analizadas algunas características de las dos principales organizaciones criminales de Brasil, CV y PCC, defendiendo que el crimen organizado en algunos países de América Latina forma parte del orden político, siendo uno de los pilares de la gobernabilidad y del mantenimiento de la exclusión social de amplios sectores de la población. A pesar del recrudecimiento de la violencia en las regiones norte y nordeste, así como en la ciudad de Rio de Janeiro, el incremento del recurso a las fuerzas armadas para atender la crisis de seguridad pública debe ser entendida en el marco del papel de los militares en el orden sociopolítico basado en la exclusión deliberada de sectores de la sociedad y el manejo político instrumental de las tensiones generadas, incluso por medio de la colusión con el crimen. En conclusión, las principales amenazas al establecimiento de la paz están en el no reconocimiento de lo que es estructural en la formación social brasileña, que es la permanencia de la sub-ciudadanía y la conciliación entre elites por el mantenimiento de la exclusión social. Este es el verdadero problema de seguridad en Brasil, el cual no puede, de ninguna manera, tener una solución militar o incluso policial.

Retomando la pregunta colocada en la introducción, entendemos que las Relaciones Internacionales - y el área de la Seguridad Internacional, en particular, ciertamente tienen valiosos aportes para realizar al estudio del crimen organizado. Nuestra intención no fue deslegitimar las investigaciones desde esta disciplina sino realizar una serie de advertencias. En primer lugar, sostuvimos que los conceptos y enfoques de la visión tradicional sobre la seguridad nacional - aun adoptando algunos elementos de las perspectivas críticas - tienden a reforzar la estrategia militarizada. La dinámica transnacional de los grupos criminales instantáneamente remite a lo global y conecta el fenómeno con los flujos entre fronteras y la política internacional. A su vez, esa conexión se hace presente en las estrategias internacionales de 
combate contra el fenómeno del crimen, aunque en parte importante dicha relación sigue los lineamientos de los intereses de los países poderosos. En función de esto defendemos una visión crítica sobre la relación que se establece entre la perspectiva securitizadora, la agenda de la cooperación internacional policial, de los esfuerzos coordinados de incautación de narcóticos en Estados Unidos y Europa y los intereses de los países consumidores netos en detrimento de los efectos que dichas estrategias tienen en los países de producción y/o tránsito. Así, entendemos que los análisis desde las Relaciones Internacionales deberían permanecer alertas a no exagerar el elemento transnacional para reclamar pertenencia disciplinar cuando el riesgo es la asociación con las perspectivas tradicional de la seguridad, militarista y estadocéntrica en relación al objeto referente.

En segundo lugar, y en conexión con lo apuntado arriba, creemos que las chances de caer en dicha exageración disminuyen cuando los internacionalistas tomamos en serio los aportes realizados por la Ciencia Política, la Sociología, la Antropología y otras ciencias sociales para entender la realidad del crimen organizado en América Latina. En este trabajo escogimos a las investigaciones sobre state-crime collusion para mostrar la naturaleza e impactos domésticos de la relación entre organizaciones criminales y estado, elementos que contradicen las premisas de la perspectiva securitizadora. Sin dudas, no somos las primeras en abordar el fenómeno desde una visión crítica sobre la seguridad, como prueban las referencias bibliográficas a colegas del área realizadas en este artículo, así como tantas otras investigaciones que ganan cada vez más espacio en las publicaciones y eventos científicos del área, a la cual esperamos haber contribuido con estas reflexiones.

\section{REFERENCIAS BIBLIOGRÁFICAS}

ABREU, Allan de. Cocaína - a rota caipira: o narcotráfico no principal corredor de drogas do Brasil. Rio de Janeiro, Record, 2018.

AMORIM, Carlos. CV-PCC: a irmandade do crime. Rio de Janeiro, Record, $14^{\mathrm{a}}$ ed, [2006] 2018. 
ARIAS, Edmond. D. Drugs and Democracy in Rio de Janeiro: Trafficking, Social Networks, and Public Security. University of North Carolina Press, 2006.

ARRUDA, João Rodrigues. O uso político das Forças Armadas e outras questões militares. Rio de Janeiro: Mauad X, 2007.

BARNES, N.. Criminal Politics: An Integrated Approach to the Study of Organized Crime, Politics, and Violence. Perspectives on Politics, 15(4), p. 967-987, 2017.

BARTOLOMÉ, Mariano C. La criminalidad organizada, un severo problema de seguridad para el hemisferio. Hemisferio, n. 11, p. 68-90, 2017.

BARTOLOMÉ, Mariano C. Más allá del crimen organizado: la reformulación del concepto Insurgencia y su impacto en el entorno estratégico sudamericano. Austral: Revista Brasileira de Estratégia e Relações Internacionais, 2(3), p. 47-77, 2013.

BARTOLOMÉ, Mariano C. La Seguridad Internacional en el Siglo XXI, más allá de Westfalia y Clausewitz. Santiago de Chile: ANEPE, 2006.

BRAGA, Camila M. Paz, Pacificação \& Proteção. Explorando o processo de paz em Timor Leste (1999-2012). Tese de Doutorado em Ciência Política. São Paulo, FFCLHUSP, 2017, digit.

BUZAN, B., \& HANSEN, L. A evolução dos estudos de segurança internacional. São Paulo: Editora Unesp, 2012.

BUZAN, B., WAEVER, O., WILDE, J. D., \& WAEVER, O. Security: A New Framework for Analysis. Lynne Rienner Pub, 1998.

CEPIK, Marco, BORBA, Pedro. Crime organizado, estado e segurança internacional. Contexto Internacional, 33(2), 375-405, 2011.

DEWEY, Matías.; MÍGUEZ, Daniel; SAíN, Marcelo. The strength of collusion: A conceptual framework for interpreting hybrid social orders. Current Sociology, v. 65, n. 3, p. 395-410, 2017.

DONADELLI, Laura M. "Segurança Multidimensional". In: SAINT-PIERRE, H. L.; VITELLI, M. G. (orgs.). Dicionário de Segurança e Defesa. São Paulo, Ed. Unesp Digital//mprensa Oficial, 2018.

FELTRAN, Gabriel. Irmãos: uma história do PCC. São Paulo, Companhia das Letras, 2018.

FERREIRA, Marcos A. S. V. Transnational Organized Crime and Structural Violence in Brazil. In: ATIENO, Christine, ROBINSON, Colin (eds.). Post-conflict Security, 
Peace and Development. Perspectives from Africa, Latin America, Europe and New Zealand. Springer International Publishing, 2019.

FERREIRA, Marcos A. S. V., FRAMENTO, Rodrigo. Degradação da Paz no Norte do Brasil: o conflito entre Primeiro Comando da Capital (PCC) e Família do Norte (FDN). Revista Brasileira de Políticas Públicas e Internacionais, v. 4 (2): 91-114, nov. 2019.

FERREIRA, Oliveiros S. Vida e morte do partido fardado. São Paulo, Senac, 2000.

GALTUNG, Johan. Tras la violência, 3R: reconstrucción, reconciliación, resolución. Afrontando los efectos visibles e invisibles de la guerra y la violencia. Gernika: Bakeaz/Gernika Gogoratuz, 2003.

GARZON, Luis F. N. Um Panorama dos últimos 25 anos no Brasil: das ressurgências neoliberais às contrarrevoluções preventivas. Revista de Estudos e Pesquisas sobre as Américas, v. 13, no 2, p. 203-229, Brasília, UnB, 2019.

HRISTOV, Jasmin. Paramilitarism and neoliberalism: Violent systems of capital accumulation in Colombia and beyond. London: Pluto Press, 2014.

KURTENBACH, Sabine.The limits of peace in Latin America. Peacebuilding, v. 7, no 3, p. 283-296, 2019.

LARANJEIRA, Ronaldo (supervisão) et. al. II Levantamento de Álcool e Drogas (LENAD) 2012. São Paulo, Instituto Nacional de Ciência e Tecnologia para Políticas Públicas de Álcool e Outras Drogas (INPAD), Unifesp, 2014.

LIMA, Renato S. Rotas da Insegurança e da Violência no Brasil. Interesse Nacional, 10(37), 38-47, 2017.

LESSING, B. Logics of Violence in Criminal War. Journal of Conflict Resolution, 59(8), p. 1486-1516, 2015.

LUGON, C. A República ‘Comunista’ Cristã dos Guaranis (1610-1768). Rio de Janeiro, Paz e Terra, $3^{a}$ ed., 1977.

MANSO, Bruno P., DIAS, Camila N. A Guerra: a ascensão do PCC e o mundo do crime no Brasil. São Paulo, Todavia, 2018.

MATHIAS, Suzeley Kalil, GUZZI, André C. Autonomia na Lei: as Forças Armadas nas Constituições Nacionais. Revista Brasileira de Ciências Sociais, 25, 41-57, São Paulo, 2010.

MATHIAS, Suzeley Kalil. "Militares já não alimentam expectativas" Entrevista com Suzeley Kalil Mathias, por Patrícia Fachin e Wagner Fernandes Azevedo. Instituto Humanitas Unisinos. Disponible en http://www.ihu.unisinos.br/592714-a- 
desestruturacao-do-estado-e-a-falta-de-expectativa-dos-militares-no-governobolsonaro-entrevista-especial-com-suzeley-kalil-mathias. Acceso en 5 de diciembre de 2019.

MOSER, Caroline ON; MCILWAINE, Cathy. Encounters with violence in Latin America: urban poor perceptions from Columbia and Guatemala. New York, NY, Routlege, 2004.

MOTTA, Bárbara V. C. Securitização. In: SAINT-PIERRE, H. L.; VITELLI, M. G. (orgs.). Dicionário de Segurança e Defesa. São Paulo, Ed. Unesp Digital/Imprensa Oficial, 2018.

MUNIZ, Jaqueline O.; PROENÇA Jr., Domício. Muita politicagem, pouca política os problemas da polícia são. Estudos Avançados, dez., 21(61), 159-172, 2007.

O’DONNELL, Guillermo. Contrapontos: autoritarismo de democratização. São Paulo, Vértice, 1986.

PEARCE, Jenny. Politics without Violence? Towards a Post-Weberian Enlightenment. Durham: Palgrave Macmillan, 2020.

Jenny. Perverse state formation and securitized democracy in Latin America. Democratization, v. 17 n. 2, p. 286-306, 2010.

PEREA, Carlos Mario. Extreme violence without war and its social reproduction implications for building peace in Latin America. Peacebuilding, v. 7, n. 3, P. 254-267, 2019.

PEREIRA, Paulo. Os Estados Unidos e a ameaça do crime organizado transnacional nos anos 1990. Revista Brasileira de Política Internacional, v. 58, n. 1, p. 84-107, 2015.

PIMENTA, Marília C. B. de Souza. Zonas Estratégicas e Estruturais para o Trânsitos Ilícitos (ZEETI): desafios à zona de paz na América do Sul. Tese de Doutorado em Relações Internacionais 'San Tiago Dantas'. Orientador: Luís Fernando Ayerbe. São Paulo, 2016, digit.

PREVOST, Gary. et al. (eds.). US National Security Concerns in Latin America and the Caribbean: The Concept of Ungoverned Spaces and Failed States. Palgrave Macmillan, 2014.

REALUYO, Celina. The Future Evolution of Transnational Criminal Organizations and the Threat to U.S. National Security. [s.I.] William J. Perry Center for Hemispheric Defense Studies, $2015 . \quad$ Disponible en https://www.academia.edu/15972830/The_Future_Evolution_of_Transnational_Crimi nal_Organizations_and_the_Threat_to_U.S._National_Security. Acceso en $\mathbf{2} 1 \mathrm{de}$ noviembre de $201 \overline{7}$. 
REALUYO, Celina. Nuevos Roles de las Fuerzas de Seguridad en la Lucha Contra el Crimen Organizado Transnacional en América. CHDS Regional Insights, 2018.

RODRIGUES, Thiago. 'Facções podem ter penetrado nas baixas patentes militares'. Entrevista a Danilo Thomaz. Revista Época, 29/06/2019. Disponible en https://epoca.globo.com/entrevista-faccoes-podem-ter-penetrado-nas-baixaspatentes-militares-23772095. Acceso en 13 de septiembre de 2019.

RODRIGUES, Thiago. Narcotráfico: uma guerra na guerra. 2.ed. São Paulo: Desatino, 2012.

RODRIGUES, Thiago; BRANCOLI, Fernando; KALIL, Mariana. "Brazil, Pacification and Major Events: Forging an "Ambience of Security" in Rio." Revista de Estudios en Seguridad Internacional, Vol. 4, No. 1, pp. 71-86, 2018.

SAÍN, Marcelo. Por qué elegimos no ver la inseguridad (aunque digamos lo contrario). Buenos Aires: Siglo XXI editores Argentina, 2017.

SAÍN, Marcelo. La regulación del narcotráfico en la provincia de Buenos Aires. [s.l.] UMET, 2015.2 Disponible en <https://www.academia.edu/23976825/La_regulaci\%C3\%B3n_del_narcotr\%C3\%A1fi co_en_la_provincia_de_Buenos_Aires>. Ācceso en 7 de mayo de 2017 .

SAÍN, Marcelo.; ARSLANIÁN, León C. Seguridad: Cambiar de paradigma es buscar en la exclusión social las causas de la violencia. Orillera, v. 2, n. 2, p. 57-67, 2017.

SAMPÓ, Carolina; TRONCOSO, Valeska. La violencia vinculada a la criminalidad en Brasil y el papel de las fuerzas armadas en la búsqueda de la seguridad pública. Revista de Relaciones Internacionales, Estrategia y Seguridad, 10, no. 1, p. 89-109, 2015.

SAINT-PIERRE, Héctor Luis. "'Defesa”ou 'Segurança'? Reflexões Em Torno de Conceitos e Ideologias." Contexto Internacional 33, no. 2, p. 407-433, 2011.

SCHWARCZ, Lilia. Sobre o autoritarismo brasileiro [e-book]. São Paulo, Cia. das Letras, 2019.

SEGURIDAD, Justicia y Paz. Las 50 ciudades más violentas del mundo 2018. Ciudad de México, marzo de 2019.2 Disponible en: http://seguridadjusticiaypaz.org.mx/files/estudio.pdf. Acceso en 6 de diciembre de 2019.

SIQUEIRA, Ítalo B. L.; PAIVA, Luiz F. S. "No Norte tem Comando": as maneiras de fazer o crime, a guerra e o domínio das prisões do Amazonas. Revista Brasileira de Sociologia, 07 (17), p. 125-154, set-dez, 2019. 
SOUZA, Jessé. A elite do atraso: da escravidão à Lava Jato. Rio de Janeiro, Leya, 2017.

SOUZA, Jessé. A tolice da inteligência brasileira. Rio de Janeiro, Leya, 2015.

SULLIVAN, John P. From Drug Wars to Criminal Insurgency: Mexican Cartels, Criminal Enclaves and Criminal Insurgency in Mexico and Central America. Implications for Global Security. Working Papers Series, 09, abr. [s.I.] Fondation Maison des sciences de l'homme, 2012.

SULLIVAN, John P.; ELKUS, Adam. State of Siege: Mexico's Criminal Insurgency. Small Wars Journal, 2008. Disponible en http://smallwarsjournal.com/ blog/journal/docs-temp/84-sullivan.pdf. Acceso en 21 de noviembre de 2017.

TORRES, Jaime. Zonas grises y delincuencia organizada transnacional: Desafíos para la soberanía del Estado en América Latina. Via luris, 27, 318-349, dez/2019. VARELLA, Drauzio. Estação Carandiru. São Paulo, Cia das Letras, 1999.

VITELLI, Marina. América del Sur: De la seguridad cooperativa a la cooperación disuasoria. Foro Internacional, 56 (225), 724-755, 2016.

WILLIS, Graham D. The Killing Consensus - Police, Organized Crime, and the Regulation of Life and Death in Urban Brazil. Oakland: University of California Press, 2015.

ZALUAR, Alba; CONCEIÇÃO, Isabel S. Favelas sob o controle das Milícias no Rio de Janeiro. Que paz? São Paulo em Perspectiva, 21(2), 89-101, 2007.

Recibido en: 23/12/2019

Aprobado en: 06/09/2020 